\title{
Commentary: When time is brain-In type A aortic dissection, team approach prevails over cannulation strategy
}

\author{
Ourania Preventza, MD, and Kim I. de la Cruz, MD
}

\footnotetext{
From the Department of Cardiovascular Surgery, Texas Heart Institute, Houston, Tex; and Division of Cardiothoracic Surgery, Michael E. DeBakey Department of Surgery, Baylor College of Medicine, Houston, Tex.

Disclosures: Authors have nothing to disclose with regard to commercial support.

Received for publication March 1, 2019; accepted for publication March 1, 2019; available ahead of print April $18,2019$.

Address for reprints: Ourania Preventza, MD, Division of Cardiothoracic Surgery, Michael E. DeBakey Department of Surgery, Baylor College of Medicine, BCM 390, One Baylor Plaza, Houston, TX 77030 (E-mail: opsmile01@aol.com).

J Thorac Cardiovasc Surg 2020;159:794-5

$0022-5223 / \$ 36.00$

Copyright (c) 2019 by The American Association for Thoracic Surgery

https://doi.org/10.1016/j.jtcvs.2019.03.030
}

Currently, no randomized trial-supported guidelines exist regarding best cannulation strategies for patients with acute type A aortic dissection complicated by preoperative cerebral malperfusion. Furthermore, no consensus exists regarding the type and timing of intervention in these patients, and current practice varies from no intervention in already comatose patients to expeditious operative intervention after quick computed tomography angiography. Hemorrhagic conversion of the ischemic area in these patients may worsen neurologic outcomes, causing significant postoperative mortality. The International Registry for Acute Dissection data suggest that among patients with acute type A aortic dissection, those who present with stroke have poorer in-hospital survival; however, those selected for surgical treatment have better late survival, and reversal of neurologic deficits has been observed.

Once a patient is determined to be an operative candidate, the best and quickest approach to establishing flow to the true lumen must be identified. In this issue of the Journal, Shimura and colleagues ${ }^{2}$ posit that echocardiographically guided central cannulation by the Seldinger technique is the quickest way to provide this flow in patients with cerebral malperfusion associated with dynamic obstruction. Shimura and colleagues ${ }^{2}$ are to be congratulated for addressing this important subject and for achieving great results with this challenging subset of patients, although the small size of their cohort and lack of a control group make it difficult to draw conclusions from their findings.

In such patients, the purpose of any cannulation strategy is to minimize cerebral ischemic injury by reperfusing the brain sooner, to avoid worsening cerebral malperfusion before the arch is repaired, and to restore cerebral and body perfusion during the ascending and arch repair. Various arterial cannulation techniques, each with its own merits, have been described by aortic centers of excellence in such cases; in cases of preoperative malperfusion, some

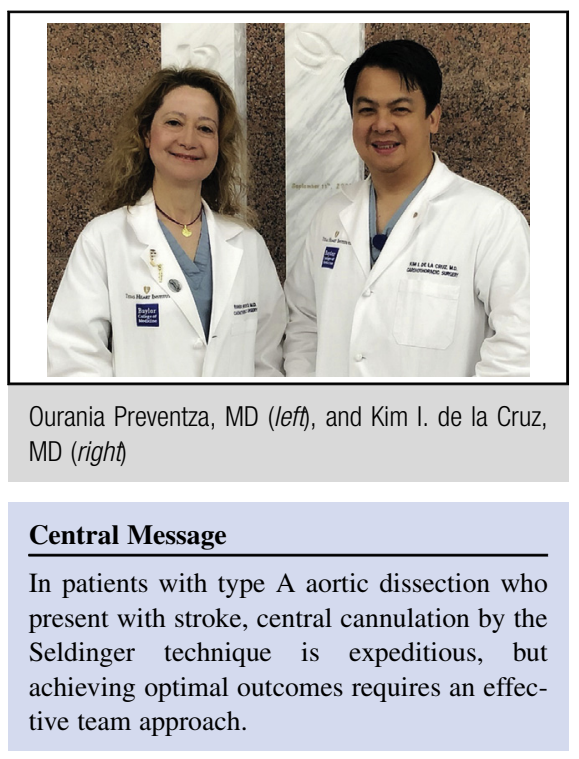

See Article page 784

have advocated inserting 2 arterial lines through the right common carotid artery (RCCA) and femoral artery in a Y-shaped circuit with a single pump, placing a temporary external shunt from the femoral artery to the RCCA, or directly perfusing the RCCA during cardiopulmonary bypass. The RCCA can be exposed in 15 minutes for quick cerebral perfusion. If the adequacy of flow is uncertain after the repair, use of the side graft originally used for cannulation as an aortocarotid bypass is an option that has been associated with excellent results. ${ }^{3}$ If cannulation is achieved through the right axillary artery, persistent malperfusion has been reported even though the arterial flow usually goes through the true and false lumens into the innominate artery. In obese patients, right axillary artery cannulation, which is easy and straightforward in slim patients, may take longer to restore flow into the ischemic brain than other alternatives, such as exposing the RCCA and direct aortic cannulation by the Seldinger technique. Orbital Doppler, near-infrared spectroscopy, electroencephalography, and transesophageal echocardiography can confirm malperfusion intraoperatively.

Directly cannulating the aortic true lumen by the Seldinger technique in patients with retrograde cerebral perfusion and deep hypothermic circulatory arrest keeps 
the operative reconstructive field free of cannulas and does not require clamping or snaring of the supra-aortic dissected vessels. Should extensive arch reconstruction become necessary, the cannulas can be moved to either carotid artery. This approach requires an experienced echocardiographer (anesthesiologist or cardiologist) to ensure the placement of the wire in the true lumen of the ascending and descending aorta. In addition, no antegrade cerebral perfusion is administered, and the temperature must be lower during the period of circulatory arrest (deep hypothermia of $17^{\circ} \mathrm{C}$ in the study of Shimura and colleagues ${ }^{2}$ ), which may have implications regarding the ensuing coagulopathy related to deep hypothermia and associated blood transfusion and its complications. In extreme situations, when the dissection is beyond the carotid bifurcation, some have stented the carotid artery in the hybrid suite, then grafted the vessel with the worst dissection to ensure quick, optimal perfusion before the temperature is reached at which hypothermic circulatory arrest is initiated.

Local expertise, having an aortic team in place, and institutional factors will determine which tailored approach is used in these cases, in which speedy brain reperfusion can be critical to minimizing the effects of cerebral malperfusion. No matter which technique one chooses, the outcomes of patients with acute type A aortic dissection who present with stroke or coma are multifactorial. The only absolute requirement for any possibility of a positive outcome in these patients is teamwork and having an aortic team in place. ${ }^{4}$

\section{References}

1. Di Eusanio M, Patel HJ, Nienaber CA, Montgomery DM, Korach A, Sundt TM, et al. Patients with type A acute aortic dissection presenting with major brain injury: should we operate on them? J Thorac Cardiovasc Surg. 2013;145(3 Suppl):213-21.e1.

2. Shimura S, Odagiri S, Furuya H, Okada K, Ozawa K, Nagase H, et al Echocardiography-guided aortic cannulation by the Seldinger technique for type A dissection with cerebral malperfusion. J Thorac Cardiovasc Surg. 2020;159: 784-93.

3. Rylski B, Urbanski PP, Siepe M, Beyersdorf F, Bachet J, Gleason TG, et al. Operative techniques in patients with type A dissection complicated by cerebral malperfusion. Eur J Cardiothorac Surg. 2014;46:156-66.

4. Preventza O. In type A aortic dissection repair, an effective team approach and relational coordination are more important for patients' outcomes than surgeon volume. J Thorac Cardiovasc Surg. 2017;154:407-8. 